\title{
A Study of College Exam Reform Based on Innovative Talents Training
}

\author{
Yingjie $\mathrm{FU}^{1, \text { a }}$ \\ ${ }^{1}$ Department of Teaching Affairs, Jilin Agricultural University, 130118, Changchun, China \\ aemail:jlaufyj@126.com
}

Key words: Innovative talents training; Exam reform; Strategy

\begin{abstract}
Deepening college exam reform is of great significance for improving college students' learning enthusiasm, promote their personality development and train innovative talents. College exam system plays a guiding role and determines the direction and quality of talent training. We must boost college exam reform constantly, under the guidance of the concept of innovative talents training.
\end{abstract}

\section{Introduction}

Education and teaching quality is a lifeline of higher education, an eternal theme of college and core of teaching work, a concentrated reflection and important symbol of teaching level and various construction levels and also a footstone for sustainable development of higher education institutions. To achieve the goal of training innovative talents, we must reform all elements inconsistent with the training requirements of "innovative talents" in traditional education ideas, teaching methods, teaching content, teaching means, teaching management, exam modes and teaching operation system, set up a talent training mode, curriculum system, teaching methods, teaching operation mechanism and exam assessment system suited to the training requirements of "innovative talents".

\section{The significance of promoting college exam reform for innovative talents training}

Reforming the exam form is the need to cultivate college students' innovation consciousness

The exam form of college courses, especially fundamental courses and humanities and social sciences courses is monotonous and cannot effectively stimulate students' initiative and creativity, but instead, make them gradually form a stereotyped "standard answers" thinking and prejudice the training of college students' innovation consciousness. Therefore, to promote the exam reform in colleges, first of all, we must diversify the exam form, combine theoretical exam and practice assessment as an organic whole, highlight practice assessment, focus on enhancing students' innovation ability and practice ability with a variety of practice assessments, such as survey report, research paper, product design, group discussion, achievement report and teaching interaction and be good at training students' thinking ability to find out and solve problems from multiple angles, channels and aspects ${ }^{[1]}$.

Reforming the exam content is the need to cultivate college students' innovation ability

Innovation ability is a core element of innovative talents. At present, the learning goal of some students is utilitarian. They often learn what is examined only and are confined to the textbook content. Their answers are standardized, which is detrimental for the training of students' divergent thinking and creative thinking, so that the students are not interested in the content expanded by their teachers. Exams play a guiding role for students, guide their learning direction and play a very crucial role in cultivating their innovation ability. So the key to promoting exam reform in colleges is to optimize the exam content ${ }^{[2]}$. Colleges must start from the characteristics of specialties, student grades and course types, etc., adjust the structure of exam content, increase the proportion of subjective questions as appropriate and focus on examining student's ability to analyze and solve problems using their knowledge.

Strengthening the exam management is the need to cultivate college students' innovative personality

At present, exam management in colleges tends to lay emphasis on the process of exam 
management, such as grasping the exam discipline and administration, etc., but ignoring the pre-thinking and post-evaluation of exam or doesn't deeply understand the significance of exam. Exam management is not entirely exam administration, but a systematic project involving paper-setting, paper review, exam organization, exam supervision, paper grading, paper analysis, result archiving and comprehensive assessment etc., which required coordinating Dean's Office, various schools, disciplines and teachers, etc. For students, an exam is an ordeal. Colleges must standardize the whole process of exam management, refine and consolidate each link in the exam management with an "educating" attitude and let students grow in every exam and get tempered in their ideology, morality and psychological quality.

\section{Existing problems with college exams}

College exams are a common system for students to complete the undergraduate training plan and earn required credits, a judgment and summary of "teaching" and "learning" between colleges and students in a certain stage and also a main reference index by which an administrative department trewards and punishes students. However, under the policy of implementing national independent innovation strategies and building an innovative nation, student-originated college exams aimed at training innovative talents generally have the following problems:

Draw a scope before exam.

Before the end of theory course, students will ask their teacher to draw a scope of exam to increase their pass rate and some teachers will reveal in the classor at the end of semester wittingly or unwittingly. The result is that students develop an inert and opportunistic psychology.

The exam form is rigid and inflexible. The content is narrow and unitary.

At present, college exam grades include ordinary grades and final exam grades, but ordinary grades only take up a small proportion. Final exam grades are the principal part. Final exam papers, especially basic theory exam papers, are stereotyped with five to six categories. The question types are fixed, rigid and inflexible. The paper setters hold on to textbooks, center on basic knowledge and basic concepts, etc., emphasize memory while ignore ability. There are few and even no questions combining theory with practice and exerting student's ability. It can't fully examine students' comprehensive level and adaptability to changes. Besides, the papers also deviate from the mission of selecting and delivering excellent innovative talents and the purpose of running the college.

The make-up exam exists in name only

Most colleges don't invigilate the make-up exam of those who fail to pass the final exam strictly. There are two reasons for this: first of all, there are only a small number of make-up examinees and the exam is invigilated by teachers in their own schools. They spare student's feelings and give them some chances, so they invigilate loosely. Secondly, a minority of teachers set the second paper to be easy. In the final exam, generally the first paper is used. Or the standard will be reduced when grading the second paper. As a result, some underachievers will defer and even default an exam with various excuses and repose on the make-up exam.

\section{Strategies and suggestions on college exam reform}

To change the exam concept.

In exam reforms, the teacher's view on exam has the greatest impact. Teachers should set up a concept that exam is an important and indispensable link in the whole teaching process and is not negligible. Teachers must take it seriously and change the emphasis on paper and ignorance of feedback and assessment in exams. For students, they should know that the setting of exams is not to obtain semester grades, but to summarize what they have learned previously. They are tests of their learning methods and a reference for further study. In colleges, teaching administrators must position the goal of exams as checking the teaching effect, checking whether the teaching goal is achieved, promoting teaching and learning through the communication of exams, consolidating students' knowledge and enhancing their ability and qualities ${ }^{[3]}$. 
To orient the exam content to ability and practice

To overcome the separation between exam content and ability assessment, the exam content must change from knowledge-oriented to a combination of knowledge, skills and ability, pay attention to assessing students' mastery of integrated knowledge and flexible use of knowledge to solve practical problems, assess their autonomous learning ability and improve the proportion of their analytical ability, innovation ability and practice ability in assessment. Only in this way will we be able to achieve the goal of training innovative talents.

To diversify exam forms

The teaching administrative department in colleges must guide teachers to start from reality and adopt flexible and varied exam forms, according to different majors, courses of different natures and characteristics and different exam purposes, encourage teachers to innovate exam forms and combine closed-book exams with open-book and semi-open-book exams, oral tests, operation, defense and short essay writing, etc. Both summative assessment and process assessment are necessary $^{[4]}$. We must shift from one-of final exams to diversified exam forms, such as multiple ordinary tests, diverse assessments and mid-term exams, so as to give full play to the role of exams.

To make the assessment criteria flexible

Using a unified assessment criterion to assess all students not only ignores students' personality development, but also makes talents cultivated by higher education lack individuality and creativity. Although the present situation of college disables us from making a different assessment scheme for each student, we can still try to improve the possibility of" aptitude-based teaching” in exams, namely, the possibility of " aptitude-based assessment ${ }^{[5]}$. This requests us to adopt flexible exam assessment criteria, improve the proportion of students' practical ability in assessment, respect students' personality development and encourage them to excel in all aspects. Even an exam paper can be divided into different difficulty levels. Students can choose different levels of questions to answer in accordance with their learning situation. In this way, we can not only find out students' learning situation, but also gain an understanding of their general situation and meet the needs of students at different levels ${ }^{[6]}$.

\section{Conclusion}

To promote exam reforms vigorously is an urgent task for current colleges to further deepen teaching reforms. The exam reform must be based on quality-oriented education and innovative talents training, establish scientific paper-setting methods, reform exam content, strengthen the examination of comprehensive quality and innovation ability, enrich exam forms and methods, reduce summative exams, increase formative exams, give full play to the diagnosis, assessment, feedback, guidance, motivation and other functions of exams, set up and perfect scientific and operable exam management systems and assessment systems and truly achieve the goal of higher education to cultivate high-quality talents.

\section{References}

[1] Ye, Xicong. Reflections on the college exam reform under the concept of innovative talents training[J] China Electric Power Education, 2012(8).

[2] Cui, Jianying. Problems and countermeasures in college exam management [J] Modern Society, 2012(8).

[3] Xu, Chunyan. Practice and discussion about vocational-technical school exam management reform [J] China Education of Light Industry, 2010 (2).

[4] Tan, Chunlan. Exploring into collegec lassroomteachingreform[J] China Market Marketing, 2014(49).

[5] Qi, Suzhen. Exploring into a scientificvocational college exam management [J] Read, Write and Count 
[6] Yao, Yong. Exploring into college quality-oriented education and college exam reform[J].Education and Vocation, 2012(3): 168-169. 